\title{
Epistemic indefinites and methods of identification
}

\author{
Maria Aloni and Angelika Port*
}

July 20, 2012

The use of plain indefinites like somebody can give rise to an ignorance implicature:

(1) Somebody arrived late.

a. Conventional meaning: Somebody arrived late

b. Ignorance implicature: The speaker doesn't know who

Epistemic Indefinites (henceforth EIs) are indefinites in which this ignorance inference is conventionalized (Jayez and Tovena, 2006; Alonso-Ovalle and MenéndezBenito, 2010). Examples of epistemic indefinite determiners are German irgendein (Haspelmath, 1997; Kratzer and Shimoyama, 2002) and Italian un qualche (Zamparelli, 2007). Sentences (2) and (3) make an existential claim, and additionally convey that the speaker does not know who the witness of this claim is. Hence, adding the continuation 'Guess who?', which would contradict the ignorance inference, results in oddity. In contrast, the plain indefinite somebody allows for this type of continuation, as illustrated in (4).

a. Irgendein Student hat angerufen. \#Rat mal wer?

Irgend-one student has called guess prt who?

b. Conventional meaning: Some student called - the speaker doesn't know who

a. Maria ha sposato un qualche professore. \#Indovina chi?

Maria has married a qualche professor guess who?

b. Conventional meaning: Maria married some professor - the speaker doesn't know who

(4) Somebody arrived late. Guess who?

In this article we provide an account of EIs cross-linguistically, focusing on

*Previous versions of this material has been presented at the workshop on Epistemic Indefinites in Göttingen, at NELS 41 (Aloni and Port, 2011), at Sinn und Bedeutung 16 (Aloni, 2012), at the MIT Linguistics colloquium and at the Workshop in Semantics and Philosophy of Language of the University of Chicago. We would like to thank the audience of these events, the editors of this volume and two anonymous reviewers for their valuable comments. This research has been funded by The Netherlands Organisation for Scientific Research (NWO). 
the German and the Italian case. The next section identifies four main functions/uses for EIs and discusses the distribution of irgendein and un qualche with respect to these functions.

\section{Functions of Epistemic Indefinites}

Epistemic indefinites are widespread across languages (Haspelmath, 1997) and interesting cross-linguistic variations can be observed in the different meanings or functions that these forms can express. Building on Haspelmath's typological survey, this section identifies four main functions (i.e. meanings and/or contexts) for EIs that will be useful for the purposes of cross-linguistic comparison.

When used specifically or under an epistemic modal EIs give rise to an ignorance effect. We will label these uses as the specific unknown (SU) function and the epistemic unknown (epiU) function respectively. In some languages EIs can also be used in negative contexts to convey narrow scope existential meanings (the negative polarity (NPI) function) or in the scope of deontic or other non-epistemic modals to convey emphatic free choice meanings (the deontic free choice (deoFC) function).

In order for an indefinite to qualify for a function, it must (i) be grammatical in the context the function specifies, and (ii) have the meaning that the function specifies. For example, any does not qualify for the SU function, because it is ungrammatical in episodic sentences, a context which forces a specific use of the indefinite (see (5)); and some does not have deontic free choice uses, because under a root modal, although being grammatical, it does not convey the universal free choice meaning specified by deoFC (see (6)).

(5) \#Mary married any doctor.

[\#spMV]

(6) You may marry some doctor.

$(\nRightarrow$ any doctor is a permissible option)

In what follow we describe the four functions in more details and discuss the distribution of irgendein and un qualche with respect to these functions.

The specific unknown function (SU) Syntactically, the specific unknown function is characterized by an unembedded use of the indefinite, ${ }^{1}$ semantically

\footnotetext{
${ }^{1}$ To distinguish between specific and non-specific uses of an indefinite we used the following continuation tests:

(i) John wants to marry a Norwegian.

a. She lives in Oslo and is 25 years old. [specific]

b. One with blond hair and blue eyes. [non-specific]

Only specific indefinites can serve as antecedents for subsequent anaphoric pronouns. This notion of specificity is sometimes labeled as scopal specificity and distinguished from epistemic specificity (e.g. Farkas, 2002). An indefinite is scopally specific when its interpretation does not depend on any quantifier or intensional predicate. An indefinite is epistemically specific if the speaker has an intended referent in mind, i.e., knows who the referent is (Fodor and Sag,
} 
by an obligatory ignorance effect: the speaker doesn't know who the intended referent of the indefinite is. Irgendein and un qualche both qualify for the SU function, as illustrated by the examples discussed in the previous section; here repeated as (7) and (8).

(7) Irgendein Student hat angerufen, (\#nämlich Peter). irgend-one student has called (\#namely Peter) 'Some student called, I don't know who'

(8) Maria ha sposato un qualche professore, (\#cioè Vito). Maria has married a qualche professor (\#namely Vito) 'Maria married some professor, I don't know who'

An interesting question concerns the type of modal inference irgendein and un qualche sustain in these examples. Following Alonso-Ovalle and MenéndezBenito (2010), we distinguish between standard free choice inference and a weaker modal variation inference:
a. Free Choice (FC): $\forall x \diamond \phi$
all alternatives in the relevant domain qualify as a possible option;
b. Modal Variation (MV): $\neg \exists x \square \phi$
more than one (but not necessarily all) alternatives in the relevant domain qualify as a possible option.

If the ignorance inference triggered by an EI is of the FC kind, (7) and (8) would imply that any student might have called and Maria might have married any professor respectively. On the weaker MV interpretation, instead, (7) and (8) would be compatible with excluding some of the epistemic possibilities. The following scenario from Alonso-Ovalle and Menéndez-Benito (2010) will help us tear the two readings apart:

Scenario: María, Juan, and Pedro are playing hide-and-seek in their country house. Juan is hiding. Pedro believes that Juan is inside the house, but not in the bathroom or in the kitchen. (Alonso-Ovalle and Menéndez-Benito, 2010, p. 6)

In this scenario, Pedro cannot truthfully utter (11), because not all the rooms are epistemic possibilities for him. Crucially, however, he could felicitously use (12) and (13), showing that irgendein and un qualche do not trigger here a FC inference, but only a weaker MV effect (see also Lauer, 2010, for similar observations).

1982). If so characterized, the specific unknown cases seem to constitute evidence that these two notions of specificity are to be kept apart: in (7) and (8) the interpretation of the indefinite is independent of any operator, but the speaker doesn't know who the intended referent is. Note however that also in these specific unknown cases there seem to be an intended referent, so also these uses seem to require that the speaker has somebody in mind. In what follows we will capture this intuition by formally distinguishing the notion of 'having somebody in mind' from the notion of 'knowing who somebody is'. 
(11) Juan might be in any room of the house, (\#but he is definitely not in the kitchen).

(12) Juan ist in irgendeinem Zimmer im Haus, aber bestimmt nicht in Juan is in irgend-one room in-the house but definitely not in der Küche.

the kitchen

'Juan is in some room of the house, but definitely not in the kitchen.'

Juan è in una qualche stanza della casa, ma sicuramente non in Juan is in a qualche room of-the house but definitely not in cucina.

kitchen

'Juan is in some room of the house, but definitely not in the kitchen.'

The epistemic unknown function (epiU) A similar ignorance effect arises when irgendein and un qualche are used under epistemic modals as illustrated in (14) and (15). We call this use the epistemic unknown function.

(14) Maria muss irgendeinen Arzt geheiratet haben.

Maria must irgend-one doctor married have

'Maria must have married some doctor, I don't know who' [epiU]

(15) Maria deve aver sposato un qualche professore.

Maria must have married a qualche professor

'Maria must have married some professor, I don't know who' [epiU]

The compatibility with the hide-and-seek scenario shows again that the modal inference in these cases is of the MV kind rather than of the stronger FC kind:

Juan muss in irgendeinem Zimmer im Haus sein, aber er ist Juan must in irgend-one room in-the house be but he is bestimmt nicht in der Küche.

definitely not in the kitchen

'Juan must be in some room of the house, but he is definitely not in the kitchen.'

Juan deve essere in una qualche stanza della casa, ma sicuramente Juan must be in a qualche room of-the house but definitely non è in cucina.

not is in kitchen

'Juan must be in some room of the house, but he is definitely not in the kitchen.'

Interestingly, when irgendein and un qualche occur under propositional attitude verbs we may find agent-oriented ignorance effects, as illustrated by the following examples:

(18) Andy glaubt, dass Maria irgendeinen Arzt geheiratet hat. Andy believes that Maria irgend-one doctor married had 
a. 'Andy believes that Maria married some doctor, I don't know who' [SU]

b. 'Andy believes that Maria married some doctor, Andy doesn't know who'

[agent-oriented epiU]

(19) Gianni crede che Maria abbia sposato un qualche professore.

Gianni believes that Maria has $s_{s u b j}$ married a qualche professor

a. 'Gianni believes that Maria married some professor, I don't know who'

$[\mathbf{S U}]$

b. 'Gianni believes that Maria married some professor, Gianni doesn't know who'

[agent-oriented epiU]

In all the cases discussed so far, irgendein and un qualche displayed a similar behavior. We turn now to cases where their behavior departs.

The Negative Polarity function (NPI) Irgendein expresses a narrow scope existential meaning in negative contexts and therefore qualifies for the negative polarity function.

Niemand hat irgendeine Frage beantwortet.

Nobody has irgend-one question answered

'Nobody answered any question'

$[\mathbf{N P I}]$

In contrast, un qualche is deviant under negation, as shown by (21) from Zamparelli (2007), and therefore does not qualify for this function.

(21) ??Non ho risposto a una qualche domanda.

Not I-have answered to a qualche question

\# 'I didn't answer any question'

$[\# \mathbf{N P I}]$

The deontic Free Choice function (deoFC) Finally, example (22) from Kratzer and Shimoyama (2002) shows that irgendein can trigger a free choice inference under deontic modals:

Maria muss irgendeinen Arzt heiraten.

Mary must irgend-one doctor marry

a. 'There is some doctor Mary must marry, I don't know who' [SU]

b. 'Mary must marry a doctor, any doctor is a permissible option' [deoFC]

Example (22) is ambiguous between a wide scope ignorance interpretation represented in (22-a) and a lower scope free choice interpretation represented in (22-b). On the latter reading, which can be forced by stressing the indefinite, the sentence doesn't appear to admit the continuation 'but definitely not doctor Schulz' confirming therefore that the modal inference in this case is of the free choice kind rather than of the weaker modal variation kind.

Maria muss IRGENDEINEn Arzt heiraten, (\#aber bestimmt nicht

Mary must irgend-one doctor marry but definitely not 
Doktor Schulz).

doctor Schulz

'Mary must marry a doctor, any doctor is a permissible option'

In contrast, un qualche never triggers a free choice inference. The most plausible interpretation for (24) is a wide scope ignorance (SU) interpretation. A non-specific interpretation is also possible, but no free choice effect is generated. ${ }^{2}$

(24) Maria deve/può sposare un qualche dottore.

Mary must/can marry a some doctor

a. 'There is some doctor Mary must/can marry, I don't know who' [SU]

b. \#'Mary must/can marry a doctor, any doctor is a permissible option' [\#deoFC]

c. 'Mary must/can marry one or other doctor' [non-specific]

To summarize, we have identified four functions an EI can exhibit:

1. SU: ignorance (MV) effect in specific uses;

2. epiU: ignorance (MV) effect under epistemic modals;

3. NPI: narrow scope existential meaning in negative contexts;

4. deoFC: free choice effect under deontic modals.

As the examples showed, German irgendein and Italian un qualche qualify for different functions. The following table illustrates the variety of (epistemic) indefinites cross-linguistically: ${ }^{3}$

\footnotetext{
${ }^{2}$ That un qualche does not give rise to free choice effects under root modals is clearly demonstrated by the following example from the web, where the continuation explicitly specifies that not any kind of basic skill is enough:

(i) Per diventare traduttore devi avere un qualche tipo di base. Di sicuro To become translator you-must have a qualche kind of basic-skill. Of sure devi saper leggere e in alcuni casi devi anche saper scrivere. you-must know read and in some cases you-must also know write.

'To become a translator you must have some basic skills. For sure you must be able to read and in some cases you also must know how to write.

${ }^{3}$ The table is based on data from Alonso-Ovalle and Menéndez-Benito (2010) for algún, Fălăuş (2009) for vreun, and Radek Šimík (p.c.) for Czech si.
} 


\begin{tabular}{|l|cccc|}
\hline & SU & epiU & NPI & deoFC \\
\hline irgendein & yes & yes & yes & yes \\
algún $(\mathrm{Sp})$ & yes & yes & yes & no \\
un qualche & yes & yes & no & no \\
-si $(\mathrm{Cz})$ & yes & no & no & no \\
vreun $(\mathrm{Ro})$ & no & yes & yes & no \\
any $(\mathrm{En})$ & no & no & yes & yes \\
qualunque (It) & no & no & no & yes \\
\hline
\end{tabular}

It is tempting to read this table as an implicational map and, along the lines of Haspelmath (1997), formulate a hypothesis of function contiguity: any indefinite in any language will always express a contiguous area of the map. If we define EIs as indefinites which exhibit at least one of the ignorance functions (SU or epiU), the map predicts that we will never find an EI which has free choice uses, but fails to have negative polarity uses. The following two would be examples of impossible distributions:

\begin{tabular}{|c|cccc|}
\hline & SU & epiU & NPI & deoFC \\
\hline$\#$ & yes & yes & no & yes \\
$\#$ & no & yes & no & yes \\
\hline
\end{tabular}

Although the validity of this hypothesis is still a matter of empirical investigation, we will assume it as a guide for our formalization. In particular by assuming that deontic free choice uses in EIs emerge as a consequence of the same mechanism that generates negative polarity uses, the impossibility of (25) will follow as one of the consequences of our analysis.

\section{Previous analyses of EIs}

Pragmatic theories In the recent literature a number of pragmatic analyses of EIs have been proposed (e.g. Kratzer and Shimoyama, 2002; Aloni, 2007; Aloni and van Rooij, 2007; Chierchia, 2010; Alonso-Ovalle and MenéndezBenito, 2010). The main idea of a pragmatic account is that the modal inferences triggered by an EI are derived as conversational implicatures based on Gricean reasoning. Pragmatic accounts are parsimonious (modal meanings of EIs follow from independently motivated principles) and therefore appealing. However, they suffer from a serious empirical problem. One of the most puzzling aspects of the data discussed above is the different behaviour irgendein displays under epistemic and deontic modals. Under epistemic modals, it gives rise to a modal variation inference, see example (14), under deontic modals it gives rise to a free choice inference, see example (22-b):

$$
\begin{aligned}
& \text { a. Epistemic: } \square_{e}(\ldots \text { irgend } \ldots) \Rightarrow \text { MV: } \neg \exists x \square_{e} \phi \\
& \text { b. Deontic: } \square_{d}\left(\ldots \text { irgend ...) } \Rightarrow \text { FC: } \forall x \diamond_{d} \phi\right.
\end{aligned}
$$

Pragmatic accounts however typically predict a uniform behaviour for an EI under epistemic and deontic modals. As an illustration, consider the analy- 
sis defended in Alonso-Ovalle and Menéndez-Benito (2010). In this analysis, irgendein is assumed to be a maximal domain widener (as in Kratzer and Shimoyama, 2002) whereas other EIs may impose different constraints on their domain of quantification, notably Spanish algún is assumed to be a minimal domain widener coming with an anti-singleton constraint. Modal inferences triggered by both kinds of EIs under epistemic or deontic modals are derived by pragmatic reasoning, as illustrated in (27) and (28).

Maximal domain widener (e.g. irgendein)

$$
\begin{array}{ll}
\text { a. Logical form: } \square_{d / e} \exists x_{D} P x & D=\{a, b, c\} \\
\text { b. } & \text { Alternatives: }\left\{\square_{d / e} \exists x_{D^{\prime}} P x \mid D^{\prime} \subset\{a, b, c\}\right\} \\
\text { c. } & \text { Negation of Alternatives: } \neg \square_{d / e} P a \wedge \neg \square_{d / e} P b \wedge \neg \square_{d / e} P c \wedge \\
& \neg \square_{d / e}(P a \vee P b) \wedge \neg \square_{d / e}(P a \vee P c) \wedge \neg \square_{d / e}(P b \vee P c) \\
\text { d. } & \text { FC inference: } \forall x_{D} \diamond_{d / e} P x
\end{array}
$$

Minimal domain widener (e.g. algún)

$$
\begin{array}{ll}
\text { a. Logical form: } \square_{d / e} \exists x_{D} P x \quad D \subseteq\{a, b, c\} \text { and } 2 \leq|D| \\
\text { b. Alternatives: }\left\{\square_{d / e} \exists x_{D^{\prime}} P x\left|D^{\prime} \subset D \&\right| D^{\prime} \mid=1\right\} \\
\text { c. Negation of Alternatives (with } D=\{a, b, c\}) \text { : } \\
\\
\text { d. } \quad \neg \square_{d / e} P a \wedge \neg \square_{d / e} P b \wedge \neg \square_{d / e} P c \\
\text { MV inference: } \neg \exists x_{D} \square_{d / e} P x
\end{array}
$$

Necessity modal sentences containing a maximal domain widener or a minimal domain widener are assumed to express the propositions (27-a) and (28-a) respectively. The former competes with the stronger alternative propositions that result from restricting the assumed maximal domain of quantification (those in $(27-b))$. The latter competes with the stronger alternatives that result from restricting the assumed non-singleton domain to a singleton set (those in (28-b)). Upon hearing the modal sentence, the hearer concludes by Gricean reasoning that all alternatives in $(27-\mathrm{b})$ or $(28-\mathrm{b})$ are false (as illustrated in (27-c) and (28-c) respectively). Together with (27-a), (27-c) entails the free choice component in (27-d), whereas (28-c), together with (28-a), only yields a weaker modal variation effect (see (28-d)). ${ }^{4}$ On this account then, assuming a maximal domain widening gives rise to a FC inference, assuming a minimal domain widening derives a weaker $\mathrm{MV}$ effect. But then irgendein, which induces maximal domain widening, will trigger a FC effect not only under deontic modals, as desired, but also under epistemic modals, contrary to the observed facts.

A further difficulty for the pragmatic approaches is that the status of FC and MV effects in EIs as conversational implicatures is at least controversial. Tests on their cancelability or reinforceability give inconclusive results (Aloni and Port, 2011). Furthermore, if the ignorance effect triggered by an EI is a plain conversational implicature, the contrast between plain indefinites and EIs as illustrated in (29) and (30) remains unexplained:

\footnotetext{
${ }^{4}$ To see why a free choice inference follows in (27), but not in (28), consider a model satisfying (27-a), but excluding the possibility of $P c$. Such model cannot satisfy (27-c), because it would contradict $\neg \square(P a \vee P b)$, but it could still satisfy (28-c).
} 
(29) Jemand hat angerufen. Rat mal wer? somebody has called guess prt who 'Somebody called. Guess who?'

(30) Irgendjemand hat angerufen. \#Rat mal wer? irgend-somebody has called guess prt who

'Somebody called - the speaker does not know who called'

We need to account for the conventionalization (or fossilization) of the ignorance effect in (30), but, with the exception of Chierchia (2010), pragmatic theories fail to address this issue and have no explanation of these facts.

Non-Gricean theories Alternative non-Gricean accounts of EIs have been defended by Jayez and Tovena (2006) and more recently by Giannakidou and Quer (2011). In these theories, ignorance effects in EIs are captured in terms of a felicity condition. As an illustration, consider (31) from Giannakidou and Quer (2011):

Referential Vagueness condition

A sentence of the form $[s, \alpha] \phi$, where $\alpha$ is a singular indefinite containing a referential vagueness marker, expresses a proposition only in those contexts $c$ where the following felicity condition is fulfilled: the speaker $s$ in $c$ does not intend to refer to exactly one individual $d$ in $c$. [Giannakidou \& Quer 2011, p.23]

At first sight (31) seems to capture the main intuition we have about ignorance uses of epistemic indefinites. However, first of all, it is unclear how these non-Gricean accounts can explain the different behaviour of irgendein under epistemic and deontic modals. Typically these theories assume a clear distinction between Free Choice indefinites and EIs. For the former, a felicity condition which derives FC effects is formulated, for the latter, one which generates MV effects. But then which felicity conditions should we formulate for irgendein? Is irgendein a FCI or an EI? Neither of the two options seems to fully explain its behaviour.

There is also a second difficulty with these approaches. In their formulation of the felicity condition they assume as given a notion of reference to individuals, but as (32) shows reference to individuals is a complex phenomenon:

$$
\begin{aligned}
& \text { Ich muss irgendeinen bestimmten Professor treffen. } \\
& \text { I must some certain professor meet } \\
& \text { 'I must meet a certain professor, but I don't know who he is' }
\end{aligned}
$$

What is surprising about this example is that it employs an epistemic determiner, irgendein, combined with a specificity marker, bestimmt (Ebert et al., 2009). The use of bestimmt seems to indicate that the speaker intends to refer to exactly one individual (at least according to the traditional view on specificity), on the other hand irgendein seems to convey that the speaker doesn't know who she is referring to. We will return to these puzzling cases below. For 
the moment it is clear that (31) should at least be refined to cover these specific unknown cases.

We turn now to our own proposal, which, as we will see, combines aspects of both the pragmatic and non-Gricean accounts we have considered here.

\section{$3 \quad$ Epistemic Indefinites and Conceptual Covers}

Along the lines of Kadmon and Landman's (1993) analysis of any, we will assume that EIs are existentials with two additional characteristics: (i) they induce an obligatory domain shift; and (ii) they express conditions that must be satisfied for the indefinite to be felicitous (felicity conditions). We will employ two different strategies to derive ignorance (MV) and deontic FC effects for EIs. Ignorance inferences will obtain as a result of the felicity conditions (rather than from Gricean reasoning) in a way similar to standard dynamic accounts to presupposition. Deontic FC inferences instead will be derived via Gricean reasoning, but will be experienced as obligatory again as a consequence of the felicity conditions. We like to think of MV and FC effects in EIs as 'fossilized implicatures': inferences, pragmatic in origin, which are now part of a lexically encoded meaning. This diachronic perspective allows us to reconcile two contrasting intuitions: on the one side, the fact that these inferences are derivable via Gricean means (a first characteristic property of conversational implicatures); and, on the other side, that these inferences are not defeasible (the negation of a second characteristic properties of conversational implicatures). In this framework, differences between different indefinites will be accounted for in terms of different domain shifts they can induce. Let us have a closer look at these possible domain shifts.

Domain shifts triggered by EIs Along the line of Zamparelli (2007) we will assume that EIs block context induced domain selections. Expanding from Zamparelli, however, we would like to propose that there are at least two ways in which a context can determine a quantificational domain.

The first way is the standard contextual domain restriction illustrated by (33). When using (33) we don't mean to quantify over the whole universe, but only over a salient set of individuals, e.g. the students in my class.

$$
\text { Everybody passed the exam. }
$$

As already observed by Kratzer and Shimoyama (2002), irgendein can block such contextual domain restrictions. As an illustration, consider the following two examples:

(34) Der Lehrer hat gefragt, ob Hans ein Buch gelesen hat. The teacher has asked whether Hans one book read has 'The teacher asked whether Hans read a book.'

Der Lehrer hat gefragt, ob Hans irgendein Buch gelesen hat. The teacher has asked whether Hans irgend-one book read has 
'The teacher asked whether Hans read any book.'

Sentence (34), which uses the plain indefinite determiner ein, conveys that the teacher asked whether Hans read a book possibly from a subset of significant books, maybe novels or scientific essays. The use of irgendein in (35) blocks such contextual restrictions and brings in marginal reading materials, such as comic books or manuals. The sentence then conveys that the teacher asked whether Hans has ever read anything at all. Along the lines of Kadmon and Landman (1993), Kratzer and Shimoyama (2002) labeled such blocking of contextual domain restrictions domain widening (henceforth DW).

There is, however, another way in which context may determine a quantificational domain, namely by the selection of a method of identification as illustrated by example (36). The blocking induced by an EI in this case will be a shift of identification method or, as we will call it, a conceptual cover shift (henceforth CC-shift). Consider the following scenario. In front of you lie two face-down cards, one is the Ace of Hearts, the other is the Ace of Spades. You know that the winning card is the Ace of Hearts, but you don't know whether it's the card on the left or the one on the right. Now consider (36):

You know which card is the winning card.

Would sentence (36) be true or false in the described scenario? Intuitively, there are two different ways in which the cards can be identified here: by their position (the card on the left, the card on the right) or by their suit (the Ace of Hearts, the Ace of Spades). Our evaluation of (36) seems to depend on which of these identification methods is adopted.

Conceptual Covers Identification methods can be formalized as conceptual covers (Aloni, 2001). A conceptual cover is a set of individual concepts which exclusively and exhaustively covers the domain of individuals.

Definition 1 [Conceptual covers] Given a set of possible worlds $W$ and a domain of individuals $D$, a conceptual cover $C C$ based on $(W, D)$ is a set of individual concepts [i.e. functions $W \rightarrow D$ ] such that:

$$
\forall w \in W: \forall d \in D: \exists ! c \in C C: c(w)=d
$$

In the card scenario described above there are at least three salient covers representing ways of identifying the cards: (37-a) representing identification by ostension, (37-b) representing identification by name, and (37-c) representing identification by description. The set of concepts in (37-d) is not an example of a conceptual cover because it does not satisfy the conditions formulated in Definition 1.
a. \{on-the-left, on-the-right
b. $\quad$ ace-of-spades, ace-of-hearts
c. $\{$ the-winning-card, the-losing-card $\}$
d. \#\{on-the-left, ace-of-spades $\}$

[ostension] [naming] [description] 
In the semantics for knowing-wh constructions proposed in Aloni (2001), the evaluation of (38) depends on which of these covers is adopted. Technically this dependence is captured by letting the wh-phrase (and other quantifiers) range over concepts in a conceptual cover rather than over plain individuals. Cover indices $n$ are added to logical form, their value is contextually supplied.

(38) You know which $n$ card is the winning card.

a. False, if $n \mapsto\{$ on-the-left, on-the-right $\}$

b. True, if $n \mapsto$ \{ace-of-spades, ace-of-hearts

c. Trivial, if $n \mapsto$ \{the-winning-card, the-losing-card $\}$

The puzzle of specific unknown uses To understand how conceptual covers relate to EIs consider again example (32), here rewritten as (39):

$$
\begin{aligned}
& \text { Ich muss irgendeinen bestimmten Professor treffen. } \\
& \text { I must some certain professor meet } \\
& \text { 'I must meet a certain professor, but I don't know who he is' }
\end{aligned}
$$

Why is this example puzzling? On the one hand, the indefinite is used specifically. Traditionally, this means that the speaker has someone in mind, i.e. she can identify the referent of the indefinite. On the other hand, the use of an EI conveys that the speaker doesn't know who the referent is, i.e. she cannot identify the referent of the indefinite.

One natural way out of this puzzle is to recognize that two identification methods are at play here: the speaker can identify on one method (for example by description) but not on another (for example naming). The main intuition of our proposal is that referents of EIs are typically identified via a method different from the one contextually required for knowledge. The notion of a CC-shift is the technical counterpart of this intuition.

Before turning to our proposal let us further illustrate how EI interplay with different methods of identification.

Methods of Identification A typical situation in which EIs are used is one in which the speaker can identify the referent by description, but not by name. Another quite typical situation is one in which she can identify by name, but not by ostension. Both cases are illustrated in the following examples.

Description and Naming: At a workshop.

a. Ich muss irgendeinen Professor treffen. Er ist der Direktor vom Institut, aber ich weiss nicht wie er heisst.

'I have to meet some professor. He is the Head of the Department, but I don't know his name'

b. Speaker-can-identify $\mapsto$ [Description], unknown $\mapsto$ [Naming]

a. Devo incontrare un qualche professore. È il capo del dipartimento, ma non so come si chiama. 
'I have to meet some professor. He is the Head of the Department, but I don't know his name'

b. Speaker-can-identify $\mapsto$ [Description], unknown $\mapsto$ [Naming]

In this scenario, the method of identification contextually required for knowledge is naming, but the referent of the EI can only be identified by description.

Naming and Ostension Again at a workshop.

a. Ich muss hier irgendeinen Professor treffen. Er heisst John Smith, aber ich weiss nicht wie er aussieht.

'I have to meet some professor here. His name is John Smith, but I don't know what he looks like'

b. Speaker-can-identify $\mapsto$ [Naming], unknown $\mapsto$ [Ostension]

a. Devo incontrare un qualche professore. Si chiama John Smith, ma non so che aspetto abbia.

'I have to meet some professor. His name is John Smith, but I don't know what he looks like'

b. Speaker-can-identify $\mapsto$ [Naming], unknown $\mapsto$ [Ostension]

In this scenario, the method of identification required for knowledge is ostension. The referent of the indefinite can only be identified by name.

In both scenarios considered the German and the Italian EIs were felicitous. The latter was a case where the speaker was able to identify by name, but not by ostension. What about the other way around? Suppose the speaker can identify by ostension, but not by name, could she still use these EIs? Consider the following scenario.

Ostension and Naming Suppose you are watching a soccer match and tell your friends:

a. Guck mal! Da ist irgendein Fussballspieler verletzt. Weisst Du wer das ist?

'Look! Some player got injured. Do you know who he is?'

b. Speaker-can-identify $\mapsto$ [Ostension], unknown $\mapsto$ [Naming]

a. ??Guarda! Un qualche giocatore si è fatto male. Sai chi è?

'Look! Some player got injured. Do you know who he is?'

b. ??Speaker-can-identify $\mapsto$ [Ostension], unknown $\mapsto$ [Naming]

In this scenario, the speaker is able to identify the referent by ostension, but not by name. Interestingly, only the German irgendein seems appropriate in this case, the Italian un qualche is odd. This contrast motivates the hypothesis we formulate in the following section.

EIs \& identification methods: Romance vs Germanic Consider the following ranking of methods of identification discussed in Aloni (2001):

$$
\text { ostension }>\text { naming }>\text { description }
$$


The preliminary observations in the previous paragraphs, in particular the contrast between (44) and (45), suggest the following hypothesis:

(47) Hypothesis: In Romance, but not in Germanic, the identification method required for knowledge must be higher in order than the identification method required for specific uses of EIs

A first consequence of (47) is that if a referent is identified by ostension, then EIs should be infelicitous in Romance, as un qualche was infelicitous in (45). This first prediction seems to be borne out as illustrated by the following 'Lambada' examples (the English and the Spanish examples are originally from AlonsoOvalle and Menéndez-Benito (2003)):

(48) Look! Some professor is dancing lambada on the table!

(49) Guck mal! Irgendein Professor tanzt Lambada auf dem Tisch! Look prt! Irgend-one professor is-dancing Lambada on the table

(50) ??Mira! Algún profesor está bailando la lambada encima de la Look! Algún professor is dancing the lambada on of the mesa! table

(51) ??Guarda! Un qualche professore sta ballando la lambada sul Look! A qualche professor is dancing the lambada on-the tavolo! table

Another prediction of (47) is that if identification by description is required for knowledge, then EIs could be felicitous in German even though the referent can be identified by ostension or naming. Again this prediction seems to be borne out as illustrated by the following example.

Ostension, Naming and Description Suppose you are a secretary in a medical practice and you have interphone with a monitor at the entrance. ${ }^{5}$ Then you say:

a. Hier ist irgendein Pharmavertreter fuer Dich. Er heisst Frank Schulz. Kann ich ihn zu Dir schicken?

'There is some pharma rep for you. His name is Frank Schulz. Can I let him in?'

b. Speaker-can-identify $\mapsto$ [Ostension/Naming], unknown $\mapsto$ [Description]

a. ??C'è qui un qualche rappresentante farmaceutico per te. Si chiama Schulz. Posso farlo entrare?

'There is some pharma rep for you. His name is Schulz. Can I let him in?'

\footnotetext{
${ }^{5}$ We have to make sure that the pharma rep can not hear the secretary speaking to the doctor, using irgendein in front of him would be very impolite.
} 


\section{b. ??Speaker-can-identify $\mapsto$ [Ostension/Naming], unknown $\mapsto$ [Descrip- tion]}

This scenario seems again to support our hypothesis. Italian un qualche seems to be sensitive to the ranking in (46), German irgendein does not. ${ }^{6}$

\section{Proposal}

In this section we sketch a formal account of the meaning and distribution of German irgendein and Italian un qualche in the framework of a Dynamic Semantics with Conceptual Covers (Aloni, 2001) along the lines of Aloni and Port (2011) and Aloni (2012). Our point of departure is the assumption that EIs are existentials with two additional characteristics: (i) they induce an obligatory domain shift; and (ii) they are licensed only if such a shift is for a reason. Differences between different EIs can be captured in terms of the different kinds of domain shift they can induce. German irgendein is assumed to be able to shift the domain of quantification in two different ways: it can either shift method of identification (CC-shift), or it can widen the domain (DW). Italian un qualche instead always triggers a CC-shift. In what follows we explain how the various uses of these indefinites can be captured in this framework. We start with the specific unknown uses.

Specific unknown uses via CC-shift In a Dynamic Semantics with Conceptual Covers (Aloni, 2001), where sentences are interpreted with respect to possible speaker information states, an existential sentence like $\exists x_{n} \phi$ asserts the existence of an individual, identified via cover $n$, which satisfies $\phi$. The main intuition of our proposal is that referents of EIs are typically identified via a method different from the one contextually required for knowledge. The notion of a CC-shift is the technical counterpart of this intuition. Suppose $m$ is the conceptual cover representing the identification method contextually required for knowledge. Then EIs signal an obligatory shift to a cover $n$ different from $m$, i.e. they existentially quantify over a cover which represents a method of identification which is not the one at play in the relevant context. Suppose now the intended referent of the indefinite were also identifiable by method $m$, a shift from $m$ to $n$ would then be vacuous in such a context. By assuming that only non-vacuous CC-shifts are justified (necessary weakening condition), we derive cover-dependent ignorance (MV) effects for specific uses of EIs, namely that the witness of the existential claim cannot be identified by the identification method at play in the context of use.

As an illustration, consider again sentence (32), here repeated as (55), used in the following scenario:

\footnotetext{
${ }^{6}$ However, if irgendein is combined with bestimmt ('certain'), its behavior is much more similar to the Romance case. See Port (2010) for some datas on this issue, which requires further investigation.
} 
SCEnARIO: At the entrance of a foreign university you are asking for directions on how to reach the room of a certain professor you have to meet.

Ich muss irgendeinen bestimmten Professor treffen.

I must irgend-one certain professor meet

'I must meet a certain professor, but I don't know who he is'

Most plausibly, the cover at play in this context is naming. Knowing the name of the professor is the most efficient way to find your way to her room. A specific use of an epistemic indefinite in such context would then signal a shift to a method of identification, say $n$, different from naming. Sentence (55), analyzed as an existential sentence in a dynamic semantics, would then say that there is a professor, identified by method $n$, that you have to meet. If the witness of this existential claim were also identifiable by naming, such CC-shift would be vacuous in this context. By assuming that only non-vacuous CC-shifts are justified, we derive that the speaker cannot identify the professor by name (see the appendix for a rigorous definition of the notions used in (56-b), by $\exists x_{n}^{\mathrm{CC}}$ we denote an existential triggering a CC-shift in a dynamic semantics).

$$
\begin{array}{ll}
\text { a. } & \text { Ich muss irgendeinen }{ }_{n} \text { bestimmten Professor treffen. } \\
& \Rightarrow \text { speaker doesn't know who } \text { wh }_{m} \\
\text { b. } & \exists x_{n}^{\mathrm{CC}}\left(\phi \wedge \square_{d} \psi\right) \models_{P} \neg \exists y_{m} \square_{e}\left(\phi \wedge \square_{d} \psi\right) \\
\text { c. } & m \mapsto \text { cover at play in context } \\
\text { d. } & n \mapsto \text { cover used to identify referent of EI } \\
\text { e. } & \text { CC-shift } \mapsto n \neq m
\end{array}
$$

Intuitively a CC-shift can be justified only when a question of identification is at issue. For example, sentence (55) raises the issue of which professor the speaker has to meet. One can felicitously utter the sentence only if one is unable to identify the professor by a contextually relevant method of identification, e.g. naming in (54). Other specific unknown uses of irgendein and un qualche are analyzed in a similar fashion. For example, our initial examples (7) and (8) raised the issue of which student called and of which professor Maria married. Again the utterances are predicted to be felicitous only in a context in which the speaker cannot identify the referent of the indefinite by a contextually relevant method of identification.

(57) a. Irgendein ${ }_{n}$ Student hat angerufen. $^{2}$

$\Rightarrow$ speaker does not know which $m$ student called

b. $\exists x_{n}^{\mathrm{CC}} \phi \models_{P} \neg \exists y_{m} \square_{e} \phi$

c. $\quad m \mapsto$ cover at play in context

d. $\quad n \mapsto$ cover used to identify referent of EI

e. $\quad$ CC-shift $\mapsto n \neq m$

(58) a. Maria ha sposato un qualche ${ }_{n}$ professore.

$\Rightarrow$ speaker does not know which $m$ professor Maria married

b. $\exists x_{n}^{\mathrm{CC}} \phi \models_{P} \neg \exists y_{m} \square_{e} \phi$ 
c. $\quad m \mapsto$ cover at play in context

d. $\quad n \mapsto$ cover used to identify referent of EI

e. $\quad$ CC-shift $\mapsto n \neq m$

Negative polarity uses via DW When an existential occurs in a negative context as in (59) no question of identification arises. CC-shifts can indeed be proven to be vacuous in these environments (see Aloni, 2001, for details).

Nobody answered any question.

By assuming that Italian un qualche always triggers a CC-shift, and CC-shifts must come for a reason, we correctly predict that un qualche does not qualify for the negative polarity function. Since CC-shifts are vacuous in these contexts, necessary weakening never obtains.

a. ??Non ho risposto a una qualche domanda.

[\#NPI]

b. $\# \neg \exists x_{n}^{\mathrm{CC}} \phi \quad$ (no reason here for CC-shift)

c. Prediction: un qualche infelicitous under negation

German irgendein instead qualifies for the NPI function. These uses are explained by assuming that irgendein can also trigger DW (as motivated in example (35)). We follow Aloni (2012) and assume that DW is justified only if it does not create a weaker statement (non-weakening condition). If the indefinite occurs in a downward entailing context, DW creates a stronger statement, and, therefore, can be justified. This explains the negative polarity uses of irgendindefinites (by $\exists y_{\text {DW }}$ we denote an existential triggering domain widening):

a. Niemand hat irgendeine Frage beantwortet.

$[\mathbf{N P I}]$

b. $\# \neg \exists x \exists y_{n}^{\mathrm{CC}} \phi$

c. $\neg \exists x \exists y_{\text {DW }} \phi$

d. Predicted meaning: "Nobody answered any question"

We turn now to the modal functions epiU and deoFC.

epiU versus deoFC One of the most striking aspects of the data discussed in this article is the distance between the two modal functions epiU and deoFC. Epistemic indefinites, notably irgendein, but also Romanian vreun (see Fălăuş, 2009), appear to display a different behavior under epistemic and deontic modals. Crucial for our account of these facts is the analysis we endorse for epistemic and deontic modality. As in standard dynamic accounts (Veltman, 1996), epistemic modals are analyzed here as non-eliminative updates which test on whether the currently accumulated information supports or is compatible with some piece of further information. In contrast, deontic modal statements that provide directly useful information about practically relevant permissions and obligations are treated as base-level informative, on a par with propositional information. Being defined in term of dynamic support, which is a CC-sensitive notion (see Aloni, 2001, for details), epistemic necessity modals 
license CC-shift in their scope. In contrast, deontic modals are defined in terms of classical truth, which is not a CC-sensitive notion, and, therefore, CC-shifts are trivialized in their scope. Thus in our framework CC-shifts can be justified under epistemic modals, but not under deontic ones. Intuitively, the use of an indefinite can indeed raise an issue of identification under the former, but not under the latter. Compare the dialogues in (62) and (63), where the continuation 'One with a lot of money' is added to force a scopally non-specific interpretation for the indefinite:

$$
\begin{aligned}
& \text { a. John must have married a Norwegian. One with a lot of money. } \\
& \text { b. Who? } \\
& \text { c. We still don't know. } \\
& \text { a. John must marry a Norwegian. One with a lot of money. } \\
& \text { b. \#Who? }
\end{aligned}
$$

While asking 'who?' can make sense after (62-a), it doesn't after (63-a). The intuitive reason behind this contrast seems to be that while from (62-a) we can infer that there exists a Norwegian that John must have married, and therefore a question of identification can arise; after (63-a) no conclusions about a specific Norwegian can be drawn, and therefore no question of identification can be raised.

Since shifts of a method of identification can be justified under epistemic modals, epiU uses of irgendein and un qualche can be explained by CC-shift in a fashion similar to the specific unknown cases discussed above. ${ }^{7}$

$$
\begin{array}{ll}
\text { a. } & \text { Maria must have married irgendein } \\
n & \text { un qualche }{ }_{n} \text { doctor. } \quad[\text { epiU] } \\
\text { speaker doesn't know } \text { who }_{m} \\
\text { b. } \quad \square_{e} \exists x_{n}^{\mathrm{CC}} \phi==_{P} \neg \exists y_{m} \square_{e} \phi \\
\text { c. } \quad m \mapsto \text { cover at play in context } \\
\text { d. } \quad n \mapsto \text { cover used to identify referent of EI } \\
\text { e. } \quad \text { CC-shift } \mapsto n \neq m
\end{array}
$$

Since shifts of a method of identification cannot be justified under deontic modals, we further predict that un qualche, which only allows for CC-shift, does not qualify for the deoFC function.

$$
\begin{aligned}
& \text { a. Maria deve sposare un qualche professore. [\#deoFC] } \\
& \text { \# 'Maria must marry a professor, any professor is a permissible } \\
& \text { option' } \\
& \text { b. } \# \square_{d} \exists x_{n}^{C C} \phi \quad \text { (no reason here for CC-shift) }
\end{aligned}
$$

Other readings of (65-a) (also non-specific ones) can be captured in this framework via (possibly non-rigidly interpreted) de re representations:

\footnotetext{
${ }^{7}$ Agent-oriented ignorance effects follow in a similar fashion by defining propositional attitude verbs in terms of support rather than truth; see appendix for details.
} 
'There is some doctor Mary must marry, I don't know who' 'Maria must marry some professor or other'

b. $\exists x_{n}^{C C} \square_{d} \phi$

A wide scope representation of non-specific uses may seem implausible, ${ }^{8}$ but has some advantages. As described in Fălăuş (2009), the Romanian epistemic determiner vreun is licensed in epistemic sentences but not in deontic or episodic sentences. By assuming that vreun disallows wide scope representations we have a preliminary account for this restricted distribution. Narrow scope representations are possible only for epistemic sentences in our framework.

a. Mary married un qualche/\#vreun professor.

b. $\exists x_{n}^{C C} \phi$

[episodic]

Mary must have married un qualche/vreun professor. [epistemic]
a. $\exists x_{n}^{C C} \square_{e} \phi$
b. $\square_{e} \exists x_{n}^{C C} \phi$

(69) Mary must marry un qualche/\#vreun professor.
a. $\exists x_{n}^{C C} \square_{d} \phi$
b. $\# \square_{d} \exists x_{n}^{C C} \phi$

[deontic]

Deontic free choice uses of irgend-indefinites, instead, constitute a potential problem for the approach. A wide scope representation for these uses doesn't seem plausible, and under deontic modals, neither CC-shift nor DW is justified. The latter fact is shown in (70-a): extending the domain of an existential under a modal leads to a weaker statement, and therefore the non-weakening condition cannot be satisfied. For this reason Aloni and Port (2011) wrongly predicted irgend-indefinites to be infelicitous under deontic modals. It is easy to see however that extending the domain of an existential under a modal no longer leads to a weaker statement if we incorporate its universal free choice inference as in $(70-\mathrm{b})$ :
a. $\square \exists x \phi=\square \exists x_{D W} \phi$
b. $\square \exists x \phi \wedge \forall x \diamond \phi \not \models \square \exists x_{D W} \phi \wedge \forall x_{D W} \diamond \phi$

without FC-inference with FC-inference

By extending Aloni and Port (2011) with an explicit mechanism of implicature derivation and incorporation, and by assuming that stress signals domain widening, Aloni (2012) predicted free choice effects to arise systematically for stressed irgend-indefinites under deontic modals:

Maria muss IRGENDEINEN Arzt heiraten.

'Maria must marry a doctor, any doctor a permissible option.'
a. $\# \exists x_{\mathrm{DW}} \square_{d} \phi$
DW cannot apply
b. $\# \square_{d} \exists x_{\mathrm{DW}} \phi$
DW cannot apply

\footnotetext{
${ }^{8}$ Eventually we would have to account for the different anaphoric potential of specific unknown and non-specific uses of the indefinite. We have to leave this issue for another occasion.
} 
c. $\square_{d} \exists x_{\mathrm{DW}} \phi+$ FCI $\quad$ with FC-inference DW can apply

Normally optional, the incorporation of free choice implicatures becomes obligatory in emphatic uses of irgend-indefinites under deontic modals: stress signals DW, but without implicature incorporation DW would be unjustified. Crucially, the straightforward method of implicature incorporation defined in Aloni (2012) works for deontic free choice implicatures, but not for epistemic ones. There is a strong intuitive difference between the kind of information deontic and epistemic inferences convey, which seems to have played a crucial role on how these inferences have been fossilized (see Aloni and Franke, 2012, for extended discussion). In particular, epistemic free choice inferences of the form $\forall x \diamond_{e} \phi$ do not survive information grow, e.g. after discovering the culprit one stops believing that anyone might have done it. As explained in details in Aloni and Franke (2012), this fact, which is made tangible in a dynamic account, prevents the possibility of incorporating epistemic free choice inferences to rescue DW uses of irgendein as it is done in (71-c) for the deontic case. But then, under epistemic modals, since DW cannot apply, CC-shift must apply and a cover-dependent modal variation effect is generated, as was illustrated in (64).

Summary of proposal To summarize, EIs are existentials with two additional characteristics:

(i) they induce an obligatory domain shift: un qualche only allows for CCshift, irgendein allows for CC-shift and DW;

(ii) they express a felicity condition: EIs are felicitous in a context iff the domain-shift they induce is for a reason:

(a) Necessary weakening condition: CC-shift is justified only if otherwise the speaker would not have been able to identify the referent of the indefinite ${ }^{9}$

(b) Non-weakening condition: DW is justified only if it does not create a weaker statement.

The analysis is implemented in a Dynamic Semantics with Conceptual Covers (Aloni, 2001) extended with an explicit mechanism of implicatures derivation and incorporation (Aloni, 2012; Aloni and Franke, 2012). See Appendix for details. Table (72) summarizes the predictions of this analysis.

\begin{tabular}{|l|cccl|}
\hline & SU & epiU & NPI & deoFC \\
\hline un qualche & yes & yes & no & no \\
irgendein & yes & yes & yes & yes \\
\hline
\end{tabular}

These predictions follow from the following facts concerning CC-shift and DW:

\footnotetext{
${ }^{9}$ Necessary weakening is formalized in terms of dynamic support. A shift from $m$ to $n$ is justified in $\sigma$ only if $\sigma \models \ldots \exists x_{n} \ldots$, but $\sigma \not \models \ldots \exists x_{m} \ldots$
} 
1. CC-shifts, when justified, yield an ignorance (MV) effect;

a. CC-shifts are not trivial (therefore can be justified) in specific uses and under epistemic modals;

b. CC-shift are vacuous (never justified) under negation and under deontic modals.

2. DW is justified only if it does not create a weaker statement

a. DW does not create weaker statements (justified) in negative contexts and under deontic modals, but only if FC implicatures are incorporated;

b. DW creates weaker statements (unjustified) in specific uses and under epistemic modals.

Fact (1a), together with (2b), explains why SU and epiU uses are predicted for both EIs; fact (1b) explains why un qualche, which only allows for CC-shifts, does not qualify for NPI or deoFC uses; and finally (2a) explains NPI and deoFC uses for irgendein.

\section{Conclusion}

Simplifying, the following implicational map seems to emerge with respect to the possible functions for EIs cross-linguistically:

$$
\text { ignorance function }>\text { negative function }>\text { emphatic free choice function }
$$

If we define EIs as indefinites which exhibit the ignorance function, the map can be read as a hierarchy, which predicts that if an EI qualifies for a function, it will also qualify for the functions which are located to the left of it in the map. In particular we will never find an EI which has emphatic free choice uses, but fails to have negative uses.

We have proposed an account of EIs as existentials triggering an obligatory domain shift. One kind of domain shift (CC-shift) produces ignorance (SU and epiU) uses and is available for all EIs. Another kind of domain shift (DW), producing negative uses, is an option only for a subset of the EIs. Emphatic free choice uses have been explained in terms of obligatory pragmatic enrichments triggered by DW under certain circumstances.

The proposed analysis predicts the generalization in (73): emphatic free choice uses presuppose the same mechanism which generates negative uses, namely DW, so whenever an emphatic free choice use is possible for an EI a negative use is also allowed. Furthermore the analysis gives rise to a number of testable predictions with respect to the acquisition and the diachronic development of EIs. For example, it predicts that with respect to an EI exhibiting all three functions, e.g. the German irgend-series, the emphatic free choice function will be acquired/emerged only after the negative polarity function. As for 
the diachronic perspective, this prediction has been confirmed by the historical corpus study reported in Port (2012).

According to the described model, emphatic free choice uses come with a high cost for the interpreter who in order to arrive at the intended interpretation needs to calculate pragmatic implicatures and consequently integrate them in the conveyed meaning. Economy then explains why the emphatic free choice function occurs at the right end of our implicational map and why many languages eventually develop specialized morphology to express free choice meaning (e.g. Romance). Typically in these languages emphatic free choice uses of EIs are blocked by the availability of a specialized free choice form which is easier to process.

Appendix Let $\mathcal{L}$ be a predicate logical language with CC-indexed variables $x_{n}, y_{m}$, ..., and three modal operators: epistemic $\square_{e}$, deontic $\square_{d}$ and $\square_{a}$ representing attitude verbs. A model $M$ for $\mathcal{L}$ is a quadruple $\left\langle W, D, R_{d}, R_{a}, C\right\rangle$ where $W$ is a set of interpretation functions for the non-logical constants in $\mathcal{L}, D$ is a non-empty set of individuals, $R_{d / a}$ is an accessibility relation over $W$, and $C$ is a set of conceptual covers based on $(W, D)$. Let $M=\left\langle D, W, R_{d}, R_{a}, C\right\rangle$ be a model for $\mathcal{L}$ and $\mathcal{V}$ be the set of variables in $\mathcal{L}$. The set $\Sigma_{M}$ of information states based on $M$ is defined as: $\Sigma_{M}=\bigcup_{X \subseteq \mathcal{V}} \mathcal{P}\left(\left(D^{W}\right)^{X} \times W\right)$. Let $i=\langle g, w\rangle$ be a possibility in a state $\sigma \in \Sigma_{M}$, then (i) $i(\alpha)=w(\alpha)$, if $\alpha$ is a non-logical constant; (ii) $i(\alpha)=g(\alpha)(w)$, if $\alpha$ is a variable in $\operatorname{dom}(g)$, undefined otherwise. Updates are defined with respect to a conceptual perspective $\wp$, which maps every CC-index $n \in N$ to some cover in $C$.

\section{Semantics}

$$
\begin{array}{rll}
\sigma\left[R t_{1}, \ldots, t_{n}\right]^{\wp} \sigma^{\prime} & \text { iff } & \sigma^{\prime}=\left\{i \in \sigma \mid\left\langle i\left(t_{1}\right), \ldots, i\left(t_{n}\right)\right\rangle \in i(R)\right\} \\
\sigma[\neg \phi]^{\wp} \sigma^{\prime} & \text { iff } & \sigma^{\prime}=\left\{i \in \sigma \mid \neg \exists \sigma^{\prime \prime}: \sigma[\phi]^{\wp} \sigma^{\prime \prime} \& i \prec \sigma^{\prime \prime}\right\} \\
\sigma[\phi \wedge \psi]^{\wp} \sigma^{\prime} & \text { iff } & \exists \sigma^{\prime \prime}: \sigma[\phi]^{\wp} \sigma^{\prime \prime}[\psi]^{\wp} \sigma^{\prime} \\
\sigma\left[\exists x_{n} \phi\right]^{\wp} \sigma^{\prime} & \text { iff } & \sigma\left[x_{n} / c\right][\phi]^{\wp} \sigma^{\prime} \text { for some } c \in \wp(n) \\
\sigma\left[\square_{e} \phi\right]^{\wp} \sigma^{\prime} & \text { iff } & \sigma^{\prime}=\left\{i \in \sigma \mid \sigma \models^{\wp} \phi\right\} \\
\sigma\left[\square_{a} \phi\right]^{\wp} \sigma^{\prime} & \text { iff } & \sigma^{\prime}=\left\{i \in \sigma \mid F(i)_{a} \models_{P}^{\wp} \phi\right\} \\
\sigma\left[\square_{d} \phi\right]^{\wp} \sigma^{\prime} & \text { iff } & \sigma^{\prime}=\left\{i \in \sigma \mid F(i)_{d} \vdash^{\wp} \phi\right\} \\
\sigma[\phi+I]^{\wp} \sigma^{\prime} & \text { iff } & \exists \sigma^{\prime \prime}: \sigma[\phi]^{\wp} \sigma^{\prime \prime} \& \sigma^{\prime}=\sigma^{\prime \prime}+\operatorname{opt}(\phi)
\end{array}
$$

\section{Auxiliary notions}

$$
\begin{aligned}
\text { c-extension: } \sigma\left[x_{n} / c\right] & =\{i[x / c] \mid i \in \sigma\} \\
i[x / c] & =\left\langle g_{i} \cup\{\langle x, c\rangle\}, w_{i}\right\rangle \quad \text { (if } x \notin \operatorname{dom}(g) \text {, undefined otherwise) } \\
F(\langle g, w\rangle)_{x} & =\left\{\langle g, v\rangle \mid w R_{x} v\right\} \\
\text { Survival: } i \prec \sigma & \text { iff } \quad \exists j \in \sigma: w_{i}=w_{j} \& g_{i} \subseteq g_{j} \\
\text { Support: } \quad \sigma \models^{\wp} \phi & \text { iff } \quad \exists \sigma^{\prime}: \sigma[\phi]^{\wp} \sigma^{\prime} \& \forall i \in \sigma: i \prec \sigma^{\prime} \\
\sigma \models_{P}^{\wp} \phi & \text { iff } \quad \sigma \models^{\wp} \phi \& \phi \text { felicitous in } \sigma \\
\text { Truth: } \quad \sigma \models^{\wp} \phi & \text { iff } \quad \forall i \in \sigma: \exists \sigma^{\prime}: \sigma[\phi]^{\wp} \sigma^{\prime} \& i \prec \sigma^{\prime} \\
\text { Entailment: } \phi \models^{\wp} \psi & \text { iff } \quad \forall \sigma, \wp: \sigma \models^{\wp} \phi \Rightarrow \sigma \models^{\wp} \psi \\
\phi \models_{P} \psi & \text { iff } \forall \sigma, \wp: \phi \& \psi \text { felicitous in } \sigma: \sigma \models^{\wp} \phi \Rightarrow \sigma \models^{\wp} \psi \\
\text { Merging: } \quad \sigma+\tau & =\left\{i \in \sigma \mid \exists j \in \tau: w_{i}=w_{j}\right\}
\end{aligned}
$$


By $\operatorname{opt}(\phi)$ we mean the set of optimal states for $\phi$ as defined in Aloni (2007). The implicatures of an utterance of $\varphi$ are defined as what is supported by any state in $\operatorname{opt}(\phi)$. Implicature incorporation, $+I$, is then straightforwardly defined as simply adding the information that is contained in all the optimal states in $\operatorname{opt}(\varphi)$ after updating with $\varphi$.

\section{References}

Aloni, M. (2001). Quantification under Conceptual Covers. Ph.D. thesis, University of Amsterdam.

Aloni, M. (2007). Expressing ignorance or indifference. Modal implicatures in BiOT. In B. ten Cate and H. Zeevat, editors, Proceedings of the Sixth International Tbilisi Symposium on Language, Logic and Computation, pages 1-20.

Aloni, M. (2012). On epistemic indefinites: a note on emphatic free choice uses. In Proceedings of Sinn und Bedeutung 16.

Aloni, M. and Franke, M. (2012). On the free choice potential of epistemic and deontic modals. In I. Caponigro and C. Cecchetto, editors, From Grammar to Meaning: The spontaneous logicality of language. Cambridge University Press.

Aloni, M. and Port, A. (2011). Epistemic indefinites crosslinguistically. In Proceedings of NELS 41 .

Aloni, M. and van Rooij, R. (2007). Free choice items and alternatives. In G. Bouma, I. Kraemer, and J. Zwarts, editors, Proceeding of the KNAW Academy Colloquium: Cognitive Foundations of Interpretaion, pages 5-26. Edita KNAW.

Alonso-Ovalle, L. and Menéndez-Benito, P. (2003). Some Epistemic Indefinites. In M. Kadowaki and S. Kawahara, editors, Proceedings NELS 33, pages 1-12, Amherst, MA. GLSA Publications.

Alonso-Ovalle, L. and Menéndez-Benito, P. (2010). Modal indefinites. Natural Language Semantics, 18, 1-31.

Chierchia, G. (2010). Meaning as an Inferential System: Polarity and Free Choice Phenomena. Draft.

Ebert, C., Ebert, C., and Hinterwimmer, S. (2009). The Semantics and Pragmatics of 'bestimmt' and 'gewiss'. In Proceedings NELS 40, Amherst, MA. GLSA Publications.

Farkas, D. F. (2002). Specificity Distinctions. Journal of Semantics, 19, 213-243.

Fodor, J. and Sag, I. (1982). Referential and quantificational indefinites. Linguistics and Philosophy, 5, 355-398.

Fălăuş, A. (2009). Polarity items and dependent indefinites in Romanian. Ph.D. thesis, University of Nantes.

Giannakidou, A. and Quer, J. (2011). Against universal free choice: free choice and referentially vague indefinites in Greek, Catalan, and Spanish. ms. 
Haspelmath, M. (1997). Indefinite pronouns. Oxford University Press, Oxford.

Jayez, J. and Tovena, L. (2006). Epistemic determiners. Journal of Semantics, 23, 217-250.

Kadmon, N. and Landman, F. (1993). Any. Linguistics and Philosophy, 16, 353-422.

Kratzer, A. and Shimoyama, J. (2002). Indeterminate pronouns: The view from Japanese. In Y. Otsu, editor, The proceedings of the Third Tokyo Conference on Psycholinguistics, pages 1-25, Tokyo. Hituzi Syobo.

Lauer, S. (2010). Some news on irgendein and algún. Talk given at the workshop 'Epistemic Indefinites', University of Goettingen.

Port, A. (2010). Epistemic specificity and knowledge. Presented at the Workshop 'Indefinites Cross-linguistically', DGfS.

Port, A. (2012). The diachronic development of German irgend-indefinites. ms.

Veltman, F. (1996). Defaults in Update Semantics. Journal of Philosophical Logic, 25, 221-261.

Zamparelli, R. (2007). On singular existential quantifiers in Italian. In I. Comorovski and K. von Heusinger, editors, Existence: Semantics and Syntax, pages 293-328. Springer. 